\title{
BASE-COMBINING CAPACITY OF COTTON
}

\author{
By Arnold M. Sookne and Milton Harris ${ }^{1}$
}

\section{ABSTRACT}

A study has been made of the base-binding capacity of cotton, using silver and calcium as the cations. Electrodialyzed dewaxed cotton was found to bind a maximum of 0.065 milliequivalent per gram of either of these cations, and electrodialyzed depectinized cotton only 0.010 milliequivalent. These values confirm previous estimates of the carboxyl contents of these samples, obtained by titration with acid. The identity of the base-binding capacities when monovalent and divalent ions are used is a strong indication that the binding of these ions results from an acid-base reaction rather than from some indefinite adsorption process. This conclusion was substantiated by esterifying the acidic groups of electrodialyzed depectinized cotton with diazomethane, which thus reduced the basebinding capacity to nearly zero.

It is shown that the maximum silver-binding capacity can be obtained only by the use of the silver salt of a very weak acid. When the salt of a strong acid is used, a sufficient number of hydrogen ions are in the solution to compete with the silver ions for the acidic groups of the fiber.

The silver-binding capacities of electrodialyzed dewaxed and electrodialyzed depectinized cotton are greater than those of dewaxed and depectinized samples, respectively. This result is explained in terms of competition of silver ions with the cations already on the acidic groups of the fiber.

The number of acidic groups in depectinized cotton is not altered by progressive treatment of the fiber with alkali, a fact which lends support to the tentative conclusion that the acidic groups in depectinized cotton are an integral part of the cellulose molecule.

\section{CONTENTS}

I. Introduction

II. Experimental procedure

1. Materials

2. Methods

(a) Determination of the silve

(b) Determination of the eqleium-binding

(c) Determination of $\mathrm{pH}$

(d) Temperature. 207

III. Results and discussion

1. Combination with silver ions _... 207

2. Combination with calcium ions 209

3. The acidic groups in depectinized cotton

IV. References.

\section{INTRODUCTION}

Cotton and other naturally occurring cellulosic materials bind acid by an exchange process in which the hydrogen ions of the acid replace the cations associated with acidic groups of the fiber $[1,2] .^{2}$ By application of this concept of ion-exchange to an investigation of the acidic properties of cotton, it has been possible to tentatively allocate the

1 Research Associates at the National Bureau of Standards, representing the Textile Foundation.

2 Figures in brackets indicate the literature references at the end of this paper. 
acidic groups to the principal constituents of the fiber [2]. Thus, in mature cotton, most of these groups are part of the pectic substance; those not in the pectic substance are assumed to be part of the cellulose molecule. Considerable interest is attached to the latter assumption, especially since, if true, it might shed some light on the complex cellulose molecule.

In order to further study the acidic properties of cotton, our earlier work has now been extended to include the direct estimation of the acidic groups in the fiber by titration with base, using both monovalent and divalent cations.

\section{EXPERIMENTAL PROCEDURE}

\section{MATERIALS}

All the measurements were made on cotton from the same batch used in the earlier work [2]. The preparation of samples of "dewaxed cotton" by extracting raw cotton with alcohol and of "depectinized cotton" by extracting dewaxed cotton with alkali has been described [2].

Some samples of dewaxed and of depectinized cotton were freed of their cationic ash by an electrodialytic procedure as follows: About $75 \mathrm{~g}$ of cotton was wetted out with a $0.01 M$ solution of hydrochloric acid at room temperature, and then electrodialyzed in a large cell until the conductance of the liquid in contact with the fiber approached that of distilled water. Quantitative determinations showed that the cationic ash of these samples was less than $0.004 \mathrm{M}$-eq/g (milliequivalent per gram). These samples will henceforth be referred to as "electrodialyzed dewaxed" or "electrodialyzed depectinized" cotton.

All samples were conditioned at $21^{\circ} \mathrm{C}$ and 65 -percent relative humidity before weighing. The moisture contents of the fibers were determined by drying representative samples at $105^{\circ} \mathrm{C}$ for 2 hours in a vacuum oven.

\section{METHODS}

(a) DETERMINATION OF THE SILVER-BINDING CAPACITY

Samples of cotton weighing about $5 \mathrm{~g}$ and containing a known amount of moisture were immersed in $100-\mathrm{ml}$ portions of solutions of silver salts at $25^{\circ} \mathrm{C}$. The amount of silver bound by the sample was determined by titration of $50-\mathrm{ml}$ aliquots of the original solution, and of the solution in equilibrium with the sample, using the Volhard method [3]. Preliminary measurements at several concentrations of silver ion indicated that equilibrium is attained in about 24 hours at $25^{\circ} \mathrm{C}$.

The solution of silver 0 -nitrophenolate used in some of the measurements was prepared by adding an excess of silver oxide to a solution of $o$-nitrophenol at $70^{\circ} \mathrm{C}$, and then filtering off the undissolved material. The silver $o$-nitrophenolate solutions were therefore saturated with respect to silver oxide.

\section{(b) DETERMINATION OF THE CALCIUM-BINDING CAPACITY}

The calcium-binding capacity was determined by the electrodialytic method previously described [4]. In the present investigation, however, a six-unit apparatus was used [5], and each of the determinations reported represents the mean of four determinations, corrected for two blanks. 
(c) DETERMINATION OF pH

$\mathrm{pH}$ values of the suspensions were measured with a McInnes and Belcher-type glass electrode and a vacuum-tube potentiometer, using a cathode-ray tube as null indicator. The $\mathrm{pH}$ values were referred to potassium acid phthalate, $0.05 M$, to which was assigned a $\mathrm{pH}$ value of 4.01 [6].

\section{(d) TEMPERATURE}

The solutions of silver salts in contact with the fiber were kept at $25^{\circ} \pm 0.02^{\circ} \mathrm{C}$.

\section{RESULTS AND DISCUSSION}

\section{COMBINATION WITH SILVER IONS}

The use of silver salts for the determination of carboxyl groups in cellulosic materials has been suggested by Rath and Dolmetsch [7]. They found that only very little silver was bound by the fibers in silver nitrate solutions but that a significant amount was bound in solutions of silver acetate. The latter salt was accordingly suggested for use in this connection. As is shown below, however, not all of the carboxyl groups bind silver when the cellulosic material is immersed in a dilute solution of silver acetate.

The combination of electrodialyzed dewaxed or depectinized cotton with silver ion may be represented by the equation

$$
\mathrm{R}-\mathrm{COOH}+\mathrm{AgA} \rightleftharpoons \mathrm{R}-\mathrm{COOAg}+\mathrm{HA},
$$

where $-\mathrm{COOH}$ represents the acidic groups of the fiber, and $\mathrm{AgA}$ represents the particular silver salt under consideration. The extent to which the reaction takes place is determined principally by the competition of silver with hydrogen ions for the acidic groups of the fiber. When silver nitrate is used, a strong acid (nitric) would be formed according to eq 1 , and this would result in a relatively high concentration of hydrogen ions. Under such conditions, not all of the acidic groups of the fiber would be expected to bind silver. If, however, a salt such as silver acetate is used, a weaker acid (acetic) is formed and accordingly a greater amount of silver is bound. When silver $o$-nitrophenolate is used, a still weaker acid (o-nitrophenol) is formed and the amount of silver bound correspondingly increases.

In dewaxed cotton, or in depectinized cotton which has been washed with calcium hydroxide, the acidic groups are already in the salt form, and the reaction of these fibers with the silver salts may therefore be represented by the following equation:

$$
\mathrm{R}-\mathrm{COOM}+\mathrm{AgA} \rightleftharpoons \mathrm{R}-\mathrm{COOAg}+\mathrm{MA},
$$

where $\mathrm{M}$ represents the cations in the cotton.

Here the extent to which the reaction takes place is determined principally by competition of silver ions with these cations for the acidic groups of the fiber. This system, however, is considerably more complex than that shown in eq 1 , since $M$ may represent a number of different cations. In addition, it must be pointed out that hydrogen ions will also be present (because of hydrolysis of the silver salts, AgA), and these will also compete for the acidic groups of the fiber. 
It is obvious that where cations are already in the fiber or where competition of hydrogen ion (formed according to eq 1) becomes appreciable, combination with silver ions may be increased by increasing the concentration of silver salt. Unfortunately, data obtained at higher concentrations of salt are subject to an error arising from the selective sorption ${ }^{3}$ of water by the fibers, and for this reason, concentrations above $0.01 M$ are avoided in the present work.

The combination of electrodialyzed dewaxed and electrodialyzed depectinized cotton as a function of concentration of silver (at equilibrium) is shown graphically in figure 1. The data were obtained in

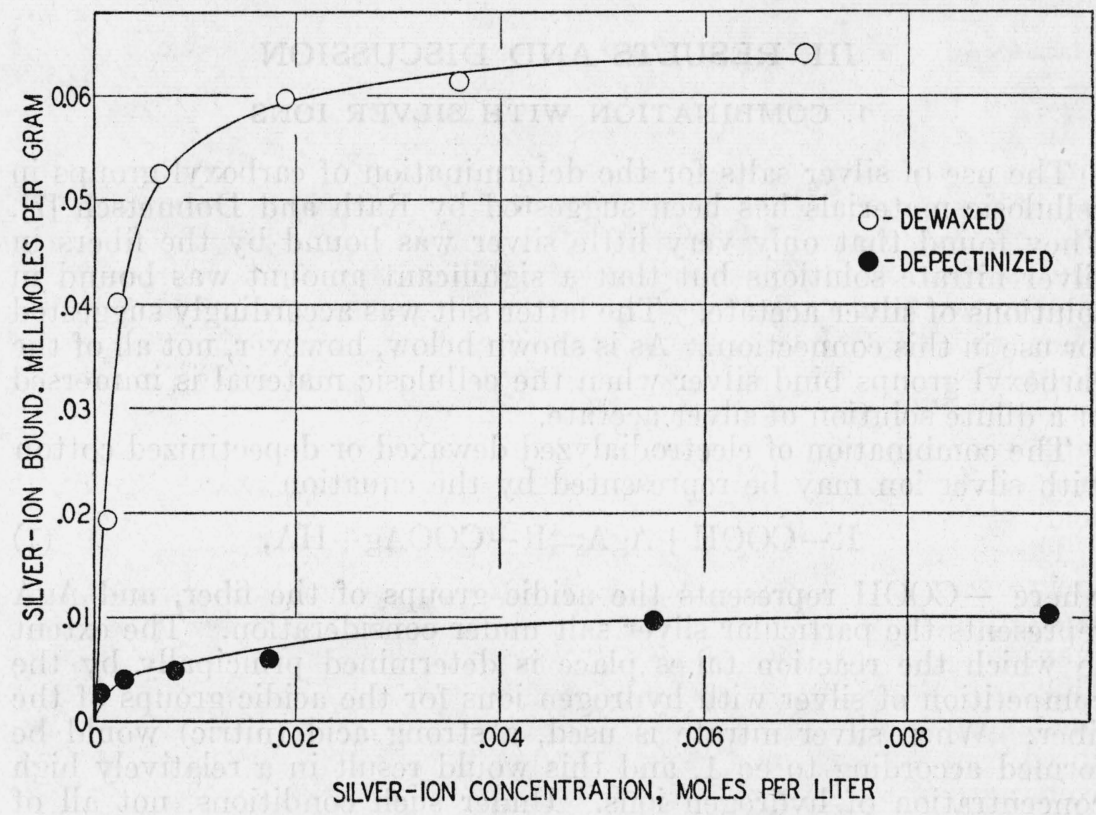

FIGURE 1.-Combination of electrodialyzed dewaxed and of electrodialyzed depectinized cotton with silver ion at $25^{\circ} \mathrm{C}$.

silver $o$-nitrophenolate solutions. The $\mathrm{pH}$ values of the solutions were high enough in all of these experiments so that there could be no appreciable combination of hydrogen ions by the acidic groups of the fiber. The flattening of the curves at higher concentrations indicates that the maximum silver-binding capacity has been approached. Since the maximum concentration of the silver-salt solutions is less than $0.01 M$, no correction for the selective sorption of water by the cotton need be made. Analysis shows that both of the curves of figure 1 conform approximately to the mass-action law, as would be expected.

Table 1 gives the results of measurements of the silver-binding capacity of the different samples of cotton which were immersed in $0.01-M$ solutions of silver nitrate, silver acetate, and silver $o$-nitrophenolate. Each of the results represents the mean of two determinations which agreed within $0.001 \mathrm{M}-\mathrm{eq} / \mathrm{g}$.

${ }^{3}$ The effect of this phenomenon and the method of correcting for it are discussed elsewhere [2]. 
TABLE 1.-Silver-binding capacity of samples soaked in $0.01 \mathrm{M}$ solutions of various silver salts

\begin{tabular}{|c|c|c|c|}
\hline Sample & Solution & $\begin{array}{l}\text { Silver } \\
\text { bound }\end{array}$ & $\begin{array}{l}\text { Equilib-- } \\
\text { rium pH }\end{array}$ \\
\hline $\begin{array}{l}\text { Electrodialyzed dewaxed cotton } \\
\text { Do } \\
\text { Do }\end{array}$ & $\begin{array}{l}\text { Silver nitrate- } \\
\text { Silver acetate } \\
\text { Silver } 0 \text {-nitrophenolate........ }\end{array}$ & $\begin{array}{r}M-e q / g \\
0.021 \\
.047 \\
.066\end{array}$ & $\begin{array}{l}3.22 \\
5.14 \\
7.12\end{array}$ \\
\hline $\begin{array}{l}\text { Dewaxed cotton } \\
\quad \text { Do } \\
\text { Do }\end{array}$ & 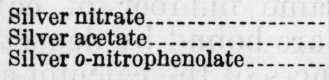 & $\begin{array}{l}.036 \\
.035 \\
.046\end{array}$ & $\begin{array}{l}5.12 \\
6.26 \\
7.60\end{array}$ \\
\hline Electrodialyzed depectinized cotton. & ......do-......... & .011 & 7.64 \\
\hline Lime-washed depectinized cotton & ........ do_. & .009 & 7.64 \\
\hline
\end{tabular}

In accord with the above discussion, it was found that the silverbinding capacities of electrodialyzed dewaxed and electrodialyzed depectinized cotton increased as the hydrogen-ion concentration of the solution in equilibrium with the samples decreased. When silver $o$-nitrophenolate was used, the final $\mathrm{pH}$ was above 7 , and accordingly the competition offered by the hydrogen ions is practically negligible. Thus, the values of 0.066 and $0.011 \mathrm{M}-\mathrm{eq} / \mathrm{g}$ obtained by titrating electrodialyzed dewaxed and electrodialyzed depectinized cottons, respectively, with this salt may be considered to be the base-binding capacities of these materials. The values obtained with this salt are in excellent agreement with the earlier estimates of the content of acidic groups [2].

The data also show that when the cotton samples are not freed of their cationic ash by electrodialysis, the maximum silver-binding capacity is not attained under the conditions of these experiments, even though the $\mathrm{pH}$ of the equilibrium solution may be above 7 . This may be explained as resulting from competition between silver ions and cations already on the fiber, as shown in eq 2 . It should be noted that according to this equation, silver ions of the solution are exchanged with cations, such as calcium, rather than with hydrogen ions. The result of this exchange should be a smaller decrease of the initial $\mathrm{pH}$ values of the solutions. The data of table 1 show that the $\mathrm{pH}$ values of corresponding solutions are indeed higher for the samples that were not electrodialyzed, and as a result, competition of hydrogen ions for the acidic groups is lowered. Thus, when silver nitrate solutions are used, the hydrogen-ion concentration of the solution in equilibrium with the dewaxed cotton is considerably lower than that of a similar solution in equilibrium with the electrodialyzed dewaxed cotton, and a corresponding difference in silver-binding capacities is observed.

\section{COMBINATION WITH CALCIUM IONS}

It has been shown elsewhere [4] that an estimate can be made of the number of acidic groups of cotton by engaging these groups with tightly held cations, such as calcium, followed by electrodialytic determination of the cation content of the sample. In the present investigation, samples of electrodialyzed dewaxed and electrodialyzed depectinized cotton were treated for 2 hours with a large excess of a $0.01 M$ solution of calcium acetate, and then washed in running distilled water for an additional 2 hours in order to remove unreacted calcium acetate. Determination of the cation contents showed that 
the electrodialyzed dewaxed sample bound 0.064 and the electrodialyzed depectinized, $0.010 \mathrm{M}-\mathrm{eq} / \mathrm{g}$ of calcium ion. Both values agree well with those obtained by titration with silver o-nitrophenolate, as well as with the earlier estimates from the acid-binding determinations [2].

\section{THE ACIDIC GROUPS IN DEPECTINIZED COTTON}

Since the same number of equivalents of calcium, silver, and hydrogen ions are bound by depectinized cotton, it may be concluded that both valences of the calcium are satisfied by the acidic groups of the fiber. This is of considerable significance, inasmuch as it strongly indicates that the phenomenon being investigated is an acid-base equilibrium and not some indefinite adsorption process. Further evidence favoring this view has resulted from another type of experiment.

When electrodialyzed depectinized fibers ${ }^{4}$ were treated for a short time with a solution of diazomethane in ether and then washed with a solution of calcium acetate, it was found that they bound less than $0.001 \mathrm{M}-\mathrm{eq} / \mathrm{g}$ of calcium. In other words, the acidic groups appear to be readily esterified by treatment with diazomethane, and are no longer available for reaction with base.

It was suggested earlier [2] that the acidic groups in depectinized cotton might well be a part of the cellulose molecule, especially since the experimental evidence did not favor the alternative possibilities that the groups might be present as the result of incomplete removal of the pectic substance or of the protein fraction during purification treatments. Assuming this to be true, the question still arises as to whether these groups were in the original cellulose or whether they were produced during the purification treatment of the fiber with alkali. In favor of the former possibility are the following experimental results. Dewaxed cotton contains $0.065 \mathrm{M}$-eq/g of acidic groups. The pectic substance of the cotton contributes $0.055 \mathrm{M}-\mathrm{eq} / \mathrm{g}$, as shown by direct uronic acid determinations [8]. The difference, $0.010 \mathrm{M}-\mathrm{eq} / \mathrm{g}$, is exactly equal to the number of acidic groups found in the depectinized cotton.

It is conceivable, of course, that the acidic groups, other than those of the pectic substance, are in substances which are removed during purification of the fiber, and that the acidic groups found were formed by oxidation of the cellulose during treatment with alkali. ${ }^{5}$ This would necessitate the formation of $0.010 \mathrm{M}-\mathrm{eq} / \mathrm{g}$ of acidic groups, the same number as would be removed during the purification treatment. Such a coincidence appears to be rather unlikely. However, if it is assumed that such a reaction does take place and proceeds slowly, then it would be expected that the content of acidic groups would steadily increase during the treatment of the fiber with alkali. Such changes would be detectable by methods described in the present paper. If the reaction proceeds very rapidly, so that it might go to completion even before complete removal of the pectic substance, the question whether the acidic groups in depectinized fibers are in the naturally occurring fiber or are produced during purification treatments cannot be answered at this time. Nevertheless, it appeared advisable to

\footnotetext{
${ }^{4}$ It is necessary to use fibers that are essentially ash-free, since the presence of cations on the acidic groups prevents their reaction with diazomethane.

$s$ Although precautions are taken to keep oxygen from the system, it is not possible under these conditions to rigorously exclude it.
} 
measure the base-binding capacity of samples purified for different lengths of time by extraction with a boiling 1-percent solution of sodium hydroxide. The results are shown in table 2 , and clearly indicate that no significant progressive changes in the acidic properties of the fiber have been produced, even after 16 hours of treatment with alkali. Thus, the possibility of slow formation of these acidic groups during the depectinizing treatments is also eliminated.

TABLE 2.-Cation-binding capacity of cotton samples as a function of duration of depectinizing treatment

\begin{tabular}{|c|c|c|}
\hline $\begin{array}{c}\text { Duration of } \\
\text { alkali treat- } \\
\text { ment }\end{array}$ & Silver bound & $\begin{array}{c}\text { Calcium } \\
\text { bound }\end{array}$ \\
\hline$h r$ & $M-e q / g$ & $M-e q / g$ \\
2 & 0.010 & 0.011 \\
4 & .010 & .009 \\
8 & .011 & .009 \\
16 & .011 & .010 \\
\hline
\end{tabular}

\section{REFERENCES}

[1] D. A. McLean and L. A. Wooten, Ind. Eng. Chem. 31, 1138 (1939).

[2] A. M. Sookne and M. Harris, J. Research NBS 25, 47 (1940) RP1313; Am Dyestuff Reptr. 29, 357 (1940); Textile Research 10, 405 (1940).

[3] J. Volhard, J. prakt. Chem. 11\%, 217 (1874).

[4] A. M. Sookne, C. H. Fugitt, and J. Steinhardt, J. Research NBS 25, 61 (1940) RP1314; Am. Dyestuff Reptr. 29, 333 (1940); Textile Research 10, 380 (1940).

[5] In preparation.

[6] D. I. Hitchcock and A. C. Taylor, J. Am. Chem. Soc. 60, 2710 (1938).

[7] H. Rath and H. Dolmetsch, Klepzig's Textil-Z. 41, 475 (1938).

[8] R. L. Whistler, A. R. Martin, and M. Harris, J. Research NBS 24, 13 (1940) RP1268; Am. Dyestuff Reptr. 29, 1 (1940); Textile Research 10, 109 (1940).

Washington, November 19, 1940. 